\title{
RETRACTED ARTICLE: Data acquisition ad hoc network system based on wireless sensor
}

\author{
Wei Lu ${ }^{1,2} \cdot$ Yuwang Yang ${ }^{1}$
}

Received: 7 January 2018 /Revised: 10 January 2018 / Accepted: 10 January 2018 /

Published online: 25 January 2018

(C) Springer Science+Business Media, LLC, part of Springer Nature 2018

The Editor-in-Chief has retracted this article [1], which was published as part of special issue "Multi-source Weak Data Management using Big Data", because there was evidence suggesting authorship manipulation and an attempt to subvert the peer review process.

The authors have not responded to correspondence about this retraction.

\section{References}

1. Lu, W. \& Yang, Y. Data acquisition ad hoc network system based on wireless sensor. Multimed Tools Appl (2018). https://doi.org/10.1007/s11042-018-5645-X

Electronic supplementary material The online version of this article (https://doi.org/10.1007/s11042-0185645-x) contains supplementary material, which is available to authorized users.

\section{Yuwang Yang}

yangyuwang_scholar@yeah.net

1 School of Computer Science and Engineering, Nanjing University of Science and Technology, Nanjing, Jiangsu 210094, China 